\title{
Physical activity in daily life, exercise capacity and quality of life in patients with Crohn's disease on infliximab-induced remission: a preliminary study
}

\author{
Andrea Lemos CABALZAR ${ }^{1}$, Felipe Meirelles de AZEVEDO ${ }^{2}$, Fernando de Azevedo LUCCA ${ }^{1}$, \\ Maycon de Moura REBOREDO² ${ }^{2}$ Carla MALAGUTI ${ }^{2}$ and Júlio Maria Fonseca CHEBLI ${ }^{1}$
}

Received 6/6/2019

Accepted 23/7/2019

\begin{abstract}
Background - Physical activity in daily life and exercise capacity have not been assessed in patients with Crohn's disease to date. Objective To evaluate the physical activity in daily life, exercise capacity, quality of life, and prevalence of mood disorders in patients with moderate-to-severe Crohn's disease on infliximab-induced remission and the possible associations among variables. Methods - A cross-sectional preliminary study was conducted. Twenty-six patients with Crohn's disease and 20 controls were selected. Participants underwent evaluation of physical activity in daily life (triaxial accelerometer), exercise capacity (shuttle walk test), handgrip strength, quality of life, and presence of mood disorders. Results - The number of steps taken (7446 \pm 3081 vs $7898 \pm 2487$ ), active time ( $80.6 \pm 42$ vs $89.7 \pm 24.3 \mathrm{~min}$ ), shuttle walk test distance [665 (405) vs 710 (409) m] and handgrip strength [31 (15) vs 29 (20) kgf did not show any difference between the patients with Crohn's disease and the controls. The time spent lying down [95.8 (68.8) vs 60.9 (74.7) min] was greater and some domains of the quality of life were superior in the patients with Crohn's disease. No correlation was observed between the physical activity in daily life and quality of life or presence of mood disorders in patients with Crohn's disease. Conclusion - Patients with Crohn's disease on infliximab-induced remission, despite to more time spent lying down, they have the same level of physical activity in daily life and exercise capacity min compared with the controls.
\end{abstract}

HEADINGS - Crohn disease. Exercise tolerance. Exercise.

\section{INTRODUCTION}

Crohn's disease (CD) is an idiopathic chronic inflammatory disorder of the gastrointestinal tract with a relapsing-remitting course $^{(1)}$. Although its etiology is not completely known, it is believed that a combination of environmental factors, intestinal microbiota modifications, and dysfunction of the mucosal immune system are involved in its development in genetically susceptible individuals ${ }^{(1)}$. Over the past 50 years, the incidence of $\mathrm{CD}$ and its prevalence rates have been increasing in countries that have adapted a "westernized" lifestyle ${ }^{(2,3)}$. It is speculated that this phenomenon can be explained, at least in part, by the impact of modifications in dietary habits and sedentary lifestyle on the composition of the gut microbiota ${ }^{(4)}$.

Physical activity has been associated with the pathogenesis of $\mathrm{CD}^{(3)}$. The benefits of physical activity to patients with CD may be due to modulation of immune function, with suppression of pro-inflammatory factors and an increase of anti-inflammatory mechanisms ${ }^{(5)}$. These benefits are associated with clinical improvement, as demonstrated by Jones et al., in a prospective study, in which level inflammatory bowel disease (IBD) patients in remission with high exercise levels presented a lower risk of flare up, compared to patients with lower exercise levels ${ }^{(6)}$. Moreover, regular exercise has other positive impacts such as improvement of nutritional and mood status, improvement of body composition and reduction of bone mineral loss, reduction of fatigue levels, and increase of quality of life $(\mathrm{QoL})^{(7)}$.

Diarrhea, abdominal pain, anorexia, and weight loss are the main symptoms of $\mathrm{CD}$, and altogether, they result in malnutrition, fatigue, sarcopenia, osteopenia, and osteoporosis ${ }^{(8,9)}$, and a higher risk of fractures ${ }^{(10,11)}$. The patients with patients encounter difficulties in exercising and frequently present a sedentary lifestyle, which may impair the control of the disease, inducing a vicious cycle ${ }^{(3,7)}$.

The use of anti-tumor necrosis factor-alpha (TNF- $\alpha$ ) agents, such as infliximab, has markedly changed the treatment of the patients with CD. It has been demonstrated that they not only elicit and maintain remission of the disease, but also reverse some of its deleterious consequences, including muscle wasting and sarcopenia that arise from chronic inflammation ${ }^{(12)}$. We hypothesized that the patients with $\mathrm{CD}$ on infliximab-induced remission have similar levels of exercise capacity and physical activity in daily life as the healthy controls. We conducted this study to assess physical activity in daily life, exercise capacity, QoL and mood disorders in outpatients with infliximab-induced remission of moderate-to-severe CD. We also investigated variables associated with physical activity in daily life.

Declared conflict of interest of all authors: JMF Chebli has served as speaker for Abbott, Abbvie, Janssen, and Takeda. Even so, JMF Chebli claims to have no conflict of interest. For the remaining authors none were declared.

Disclosure of funding: Partially supported by Fundação de Amparo à Pesquisa do Estado de Minas Gerais (FAPEMIG), Conselho Nacional de Desenvolvimento Científico e Tecnológico (CNPq) and by the Coordenação de Aperfeiçoamento de Pessoal de Nível Superior - Brasil (CAPES) - Finance Code 001.

1 Universidade Federal de Juiz de Fora, Faculdade de Medicina, Departamento de Gastroenterologia, Hospital Universitário, Centro de Doenças Inflamatórias Intestinais, Juiz de Fora, MG, Brasil. ${ }^{2}$ Universidade Federal de Juiz de Fora, Faculdade de Fisioterapia, Programa de Pós-Graduação Ciências da Reabilitação e Desempenho Físico-Funcional, Juiz de Fora, MG, Brasil. Corresponding author: Carla Malaguti. E-mail: carlamalaguti@gmail.com 


\section{METHODS}

\section{Study design}

This cross-sectional preliminary study was conducted between December 2014 and November 2016 at the University Hospital of the Federal University of Juiz de Fora, Brazil.

\section{Participants}

Volunteers were recruited from patients of the Inflammatory Bowel Disease Outpatients Clinic (CD group) and the General Gastroenterology Outpatients Clinic (control group) of the hospital. In both cases, patients who presented at the clinics for scheduled medical appointments were assessed regarding study eligibility and invited to participate. We recruited control group subjects with functional dyspepsia since these are comparators of the same socioeconomic status as users of a University Hospital.

All procedures performed in studies involving human participants were in accordance with the ethical standards of the institutional and/or national research committee and with the 1964 Helsinki declaration and its later amendments, or comparable ethical standards. The Ethics Review Board of the institution approved the study under $\mathrm{n}^{\circ} 95.125$ and informed consent was obtained from all individual participants in the study.

The patients with CD were included if they were 18 years of age or older and presented moderate-to-severe disease in infliximabinduced clinical remission over for at least six months. The diagnosis of CD was based on clinical, radiologic, endoscopic, and histopathological criteria ${ }^{(13)}$, and its severity was defined based on the CD activity index score and symptomology, according to European Crohn's and Colitis Organization guidelines on the diagnosis and management of $\mathrm{CD}^{(13)}$. Clinical remission was defined by a HarveyBradshaw Index (HBI) of less than $5^{(14)}$. The control group was recruited from asymptomatic patients with diagnosis of functional dyspepsia, defined by the ROME IV diagnostic criteria ${ }^{(15)}$.

We excluded patients who have presented active CD (HBI $\geq 5)$ during the last six months despite infliximab therapy, those who had mild CD, those who had articular, neurologic or neuromuscular disease, short-bowel syndrome; and those with a stoma. In both groups, we excluded participants who had severe comorbidities, such as cardiopulmonary disease, hepatic disease, end-stage renal disease and active malignancy (except cutaneous), and obesity grade II. Pregnant or nursing women, and those who wanted to become pregnant during the study were not selected.

\section{Measurements and outcomes}

After obtaining written informed consent, patients' anthropometric, medical and socio-demographic data were collected. We also obtained disease-associated variables, including duration of disease, location and phenotype of CD according to the Montreal classification, and activity of the disease measured according to the $\mathrm{HBI}^{(16)}$.

\section{Physical activity in daily life}

Physical activity in daily life was monitored by a DynaPort activity monitor (McRoberts BV, The Hague, Netherlands), a tri axial accelerometer that measures the time spent in different activities and positions (standing, walking, lying down and sitting), and the number of steps taken. Patients were instructed to place the accelerometer at the waistline and to wear it during the waking periods (12-hour periods) of four consecutive days, including one day of the weekend, except during showers and water activities.
Patients were instructed to maintain normal activity behavior while using the device ${ }^{(17)}$.

The modified Baecke questionnaire, validated for the Brazilian population, was applied to measure self-reported physical activity. It includes questions about household activities, sports, and leisure time during the last 12 months, as previously described ${ }^{(18)}$. The sum of the results of the three separated domains yields a final score that classifies the patients into: sedentary $(<9)$; active $(9-16)$ or athletic $(>16)$.

\section{Exercise capacity}

Exercise capacity was evaluated by the shuttle walking test $(\mathrm{SWT})^{(19)}$. In SWT the patient is instructed to walk up and down a $10 \mathrm{~m}$ course separated by cones. An audio sign dictates the speed of which the patient is supposed to walk. Every minute the walking speed increased by a small increment. The test was stopped when the patient was unable to maintain the required speed or showed any symptoms. The total distance indicated the exercise capacity. Vital signs, such as heart rate, blood pressure, and peripheral oxygen saturation were recorded. The modified Borg scale score for evaluation of dyspnea and fatigue was measured before and after $\mathrm{SWT}^{(20)}$.

\section{Peripheral muscle strength}

Handgrip strength (HS) is a simple and objective test that evaluates the function of skeletal muscle. HS was performed with a hydraulic dynamometer (SAEHAN, Korea), according to American Society of Hand Therapists recommendations ${ }^{(21)}$. Three values were obtained with the dominant hand, and the highest value was compared to the normality table based on sex and age ${ }^{(22)}$.

\section{Quality of life}

The QoL was assessed both by the Short Form 36 Healthy Survey (SF-36) and the Inflammatory Bowel Disease Questionnaire (IBDQ), which were previously translated and validated in Brazil $^{(23,24)}$. SF-36 is comprised of 36 questions that gather data on: physical health, such as physical functioning, role-physical, bodily pain, and general health; and components related to mental health, specifically, vitality, social functioning, role-emotional and mental health in general. The answers to these questions in each domain are assigned a numerical score, which is coded and classified on a scale from 0 to 100 , with 100 being the highest QoL ${ }^{(23)}$. IBDQ is a specifically designed questionnaire that evaluates the QoLof patients with IBD. It is made up of 32 questions that evaluates different aspects of health quality gathered into four domains: intestinal symptoms, systemic symptoms, social and emotional functions. The score is based on the Likert scale that ranges from 1 to 7 , with 1 being the worst state and 7 the best QoL. All the domains are grouped and summed up giving the global score ${ }^{(24)}$.

\section{Anxiety and depression}

Anxiety and depression levels were assessed using the Hospital Anxiety and Depression Scale (HADS), validated for the Brazilian population ${ }^{(25)}$. It screens for clinically significant anxiety and depressive symptoms in medically ill patients. HADS is composed of 14 items, equally divided into anxiety and depression-related questions. Each item is rated on a 4-point scale, ranging from 0 (no impairment) to 3 (highest impairment). Anxiety and depression scores are considered as the sum of the respective items, ranging from 0 to 21. According to the validated translations of HADS, the cutoff value for depressive or anxiety symptoms is 8 . 


\section{Statistical analysis}

Statistical analysis was performed using SPSS 20.0 (SPSS, Chicago, IL, USA). Initially, normal distribution was validated using a Kolmogorov-Smirnov test. Data were expressed as mean \pm standard deviation or median (interquartile range) for symmetrically and asymmetrically distributed data, respectively. Comparisons of frequencies were done by using the $\chi$-squared statistic with Yates' correction. Mean values between two groups were compared using an unpaired Student's $t$-test or Mann-Whitney U test, for normally and non-normally distributed variables, respectively. Pearson or Spearman correlation coefficients, were used to analyze the relationship between the number of steps/day and other variables of interest. The level of statistical significance was set at $P<0.05$.

\section{RESULTS}

Of the 45 patients screened in the $\mathrm{CD}$ group, 26 were included. In the control group, of 40 patients screened, 20 were included (FIGURE 1). Both groups had similar characteristics, except for a lower body mass index in the CD group (TABLE 1).

The most common location of resection was ileocolic (53.8\%) and most patients with $\mathrm{CD}$ did not have a history of intestinal resection $(73.1 \%)$. Perineal disease was observed in only $5(19 \%)$ patients.

FIGURE 2 shows the time spent per day in different activities for both groups. The patients with CD spent more time lying down than the control subjects [ $116.3 \pm 107.3$ vs $63.7 \pm 55.7 \mathrm{~min}$; the median values and quartiles were as follows: 95.8 (68.8) vs 60.9 (74.7); $P=0.046$ and $P=0.010$, respectively].

There were no significant differences between the groups regarding the time spent walking, standing, or sitting. In addition, the number of steps/day values were similar between the groups (CD group vs control group $7446 \pm 3081$ vs $7898 \pm 2487 ; P=0.63$ ).

The self-reported physical activity was measured by the modified Baecke questionnaire and did not differ between the groups of $\mathrm{CD}$ and controls with respect to all domains and the total score [7.24 (4.62) vs 7.13 (4.37), respectively; $P=0.19]$.

There was no difference in the distance walked in the SWT between the groups [median values and quartiles: $\mathrm{CD}$ group vs control group 665 (405) vs 710 (409) $\mathrm{m} ; P=0.77]$. The HS test results were similar between the groups $\mathrm{CD}$ and controls [median values and quartiles: 31 (15) vs 29 (20) $\mathrm{kgf} ; 79.6 \pm 17.9$ vs $79 \pm 24 \%$ pred of $\mathrm{kgf}$, respectively; $P=0.54$ compared to absolute values and $P=0.90$ to predicted values of normality]. Data are presented in median and on average according to the distribution of the variables.

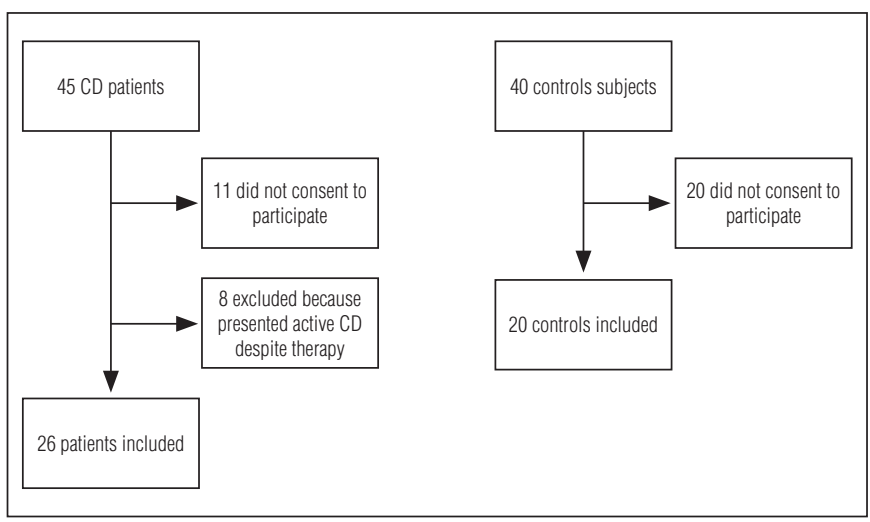

FIGURE 1. Flow diagram of participants in the study.
TABLE 1. Demographic and clinical characteristics of Crohn's disease (CD) patients and controls.

\begin{tabular}{lccc}
\hline & CD (n=26) & $\begin{array}{c}\text { Control } \\
(\mathbf{n}=20)\end{array}$ & $P$ values \\
\hline $\begin{array}{l}\text { Gender } \\
\quad \text { Female } \\
\text { Male }\end{array}$ & $14(53.8)$ & $12(60.0)$ & \\
& $12(46.2)$ & $8(40.0)$ & 0.68 \\
Race & & & \\
$\quad$ Caucasian & & & \\
$\quad$ Non-white & $25(96.2)$ & $17(85.0)$ & 0.19 \\
& $1(3.8)$ & $3(15.0)$ & \\
Age (years) & & & \\
Body mass index $\left(\mathrm{kg} / \mathrm{m}^{2}\right)$ & $23.5 \pm 2.8$ & $27.6 \pm 4.9$ & 0.001 \\
Smokers (n, \%) & $8(30.7)$ & $4(20)$ & 0.19 \\
Formal work $(\mathrm{n}, \%)$ & $12(46.1)$ & $11(55.0)$ & 0.56 \\
HBI & $1(4.0)$ & - & -
\end{tabular}

IBDQ domains

Intestinal symptom

Systemic symptom

Social function

Emotional function

Total

$64.0(44.0)$

$29.5(20.0)$

$33.0(22.0)$

$70.0(39.0)$

$198.5(113.0)$

Phenotype of CD

$\begin{array}{lc}\text { B1 }(\mathrm{n}, \%) & 11(42.3) \\ \mathrm{B} 2(\mathrm{n}, \%) & 7(26.9) \\ \mathrm{B} 3(\mathrm{n}, \%) & 8(30.7)\end{array}$

Disease location

$\begin{array}{lc}\text { L1 }(\mathrm{n}, \%) & 6(23.1) \\ \text { L2 }(\mathrm{n}, \%) & 4(15.4) \\ \text { L3 }(\mathrm{n}, \%) & 14(53.8) \\ \text { L4 (n, \%) } & 2(7.7) \\ \text { Disease duration (years) } & 4(21.5)\end{array}$

$-$

$-$

$-$

$-$

Disease duration (years)

$4(21.5)$

$5(19.2)$

Perianal disease (n, \%)

$7(26.9)$

$(\mathrm{n}, \%)$

Data expressed as absolute and relative values and mean $\pm \mathrm{SD}$ or median (interquartile range) for symmetrically and asymmetrically distributed data, respectively.

HBI: Harvey-Brashaw index; L1: ileal; L2: colonic; L3: ileocolonic; L4: isolated upper digestive; B1: non-stricturing, non-penetrating; B2: stricturing; B3: penetrating; IBDQ: inflammatory bowel disease questionnaire.

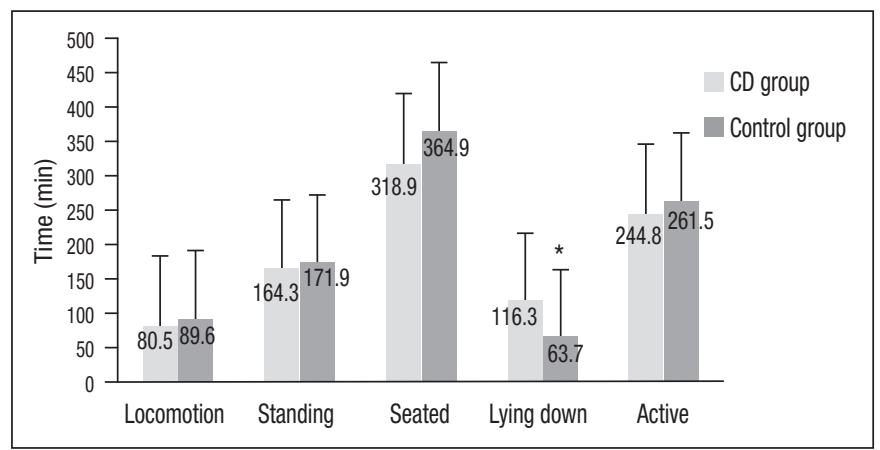

FIGURE 2. Comparison of time spent per day in different positions and functional activities in Crohn's disease (CD) and control groups. *CD patients spent more time lying down compared with control subjects $(P=0.04)$. 
The control patients showed lower SF-36 scores in the pain, vitality, social aspects, and mental health domains compared to the patients with $\mathrm{CD}(P<0.05)$. There were no significant differences regarding anxiety and depression scores measured by HADS (TABLE 2).

TABLE 2. Quality of life and psychological scores in Crohn's disease patients $(\mathrm{CD})$ and controls.

\begin{tabular}{lccc}
\hline & $\begin{array}{c}\text { CD Group } \\
(\mathbf{n}=26)\end{array}$ & $\begin{array}{c}\text { Control Group } \\
(\mathbf{n}=20)\end{array}$ & $\boldsymbol{P}$ values \\
\hline SF-36 domains & & & \\
$\quad$ Functional capacity & $95(50.0)$ & $95(85.0)$ & 0.82 \\
Physical aspects & $100(100.0)$ & $100(100.0)$ & 0.30 \\
Pain & $78(80.0)$ & $46(100.0)$ & 0.003 \\
General health status & $67(70.0)$ & $58.5(52.0)$ & 0.32 \\
Vitality & $70(80.0)$ & $60(70.0)$ & 0.03 \\
Social aspects & $93.7(75.0)$ & $56.2(100.0)$ & 0.03 \\
Emotional aspects & $100(100.0)$ & $100(100.0)$ & 0.23 \\
Mental health & $76(68.0)$ & $68(80.0)$ & 0.04 \\
HADS & & & \\
Anxiety & $6(14.0)$ & $7(17.0)$ & 0.07 \\
Depression & $3(9.0)$ & $5(15.0)$ & 0.09 \\
\hline
\end{tabular}

Data are expressed as median (interquartile range)

SF-36,:Short Form 36 Healthy Survey; HADS: Hospital Anxiety and Depression Scale.

No correlation was observed between the level of physical activity and the IBDQ QoL $(\mathrm{r}=-0.25 ; P=0.21)$, anxiety scores $(\mathrm{r}=0.24$; $P=0.23)$, or depression scores of the HADS ( $\mathrm{r}=-0.48 P=0.21)$.

\section{DISCUSSION}

This study evaluated the physical activity in daily life, exercise capacity, QoL and mood disorders in patients with CD during infliximab-induced remission compared to control subjects. We found that patients with CD present the same level of physical activity in daily life and exercise capacity when compared to controls, but higher scores in the pain, vitality, social aspects and mental health domains of the SF-36 questionnaire.

An explanation for the same level of physical activity in daily life shown by the patients with $\mathrm{CD}$ as the controls is that they were evaluated during the quiescent phase of the disease, in which the symptoms that could lead to a sedentary lifestyle, such as fatigue, muscular and joint pain, and fecal incontinence, are usually ab$\operatorname{sent}{ }^{(26)}$.

Studies objectively evaluating the level of physical activity in patients with CD are still scarce. Only one of them used an accelerometer in the evaluation of physical activity and showed that patients with CD have sub-optimal physical activity compared to a healthy control group ${ }^{(27)}$. However, this was a cross-sectional study with a small sample size, with many patients not in clinical or infliximab-induced remission.

A recent article from our group showed muscle functional impairment and poorer quality of life in patients with $\mathrm{CD}$ compared to healthy controls ${ }^{(28)}$. However, the control group consisted of healthy volunteers and the $\mathrm{CD}$ group was formed by patients in the active phase of the disease, different from the present study. Another explanation for the physical activity in daily life among the patients with CD might be the effects of the anti-TNF- $\alpha$ therapy on factors of the disease that could impact exercise capacity. High levels of TNF- $\alpha$ have been associated with muscular cell death, sarcopenia, and cachexia in the patients with $\mathrm{CD}^{(12)}$. In contrast, anti-TNF- $\alpha$ therapy with infliximab has been shown to reverse some of these dysfunctions, with improved nutritional status ${ }^{(29)}$ and reversion of inflammatory sarcopenia ${ }^{(2)}$. In accordance with these studies, our patients, who were in remission, presented normal nutritional status, based on their body mass index; and normal peripheral muscle strength, based on their HF results. Moreover, their exercise capacity was similar to the control group, as observed in SWT; and therefore, was not a limitation to physical activity among the patients with $\mathrm{CD}$ in remission.

Anti-TNF- $\alpha$ therapy also can have a positive effect on QoL in patients with $\mathrm{CD}$. It is well known that $\mathrm{QoL}$ in patients with IBD, a majority of which have $\mathrm{CD}$, is impaired, but this was not observed in our current study. However, randomized clinical trials have shown that treatment with biological therapy can significantly improve the QoL of patients only after a few months of treatment and lasting for a long period of time ${ }^{(30-34)}$. For instance, Feagan et al. ${ }^{(30)}$. found that baseline scores for a pooled patient population (335 patients) indicated substantial impairment in QoL and after a short period of infliximab therapy, there was significant improvement in IBDQ and SF-36 scores. The authors also showed that scores higher than 170 points in IBDQ corresponded to symptomatic remission of $\mathrm{CD}$. The findings of the current study are in accordance with these findings, since patients with $\mathrm{CD}$ showed higher scores in some domains of the SF-36 questionnaire compared to the control group. We hypothesized that the occurrence of lower QoL in the control group could be explained by the visceral hypersensitivity present in functional dyspepsia patients ${ }^{(35)}$. This control group most likely became more responsive to symptoms than patients with $\mathrm{CD}$ that recently to achieved remission.

From a clinical point-of-view, patients with $\mathrm{CD}$ should be motivated to increase their level of physical activity in daily life. Even though most patients with CD in this study were classified as somewhat active based on steps/day, $53.8 \%$ of these patients did not reach the minimum 7500 steps/day to be characterized as active. It is noteworthy that exercise programs for IBD patients are well tolerated with decreases of disease activity, and functional gains leading to an increased QoL and improved mood ${ }^{(35)}$. Regular physical activity also improves body composition and decreases fatigue in these patients ${ }^{(35)}$. Furthermore, several epidemiological studies have linked physical activity during the pre-illness period with reduced risk of IBD onset ${ }^{(36-41)}$, and during the illness phase as a possible preventive factor for $\mathrm{CD}$ flare ups ${ }^{(36)}$. It is conceivable that regular moderate aerobic and/or resistance exercises may improve the health status of patients with IBD both by modulating immune function and by improving physical function ${ }^{(35)}$.

There are a few limitations that should be taken into consideration to adequately qualify our results. Firstly, we did not evaluate the direct effect of infliximab therapy on physical activity in daily life and exercise capacity since a cross-sectional study design was used. Longitudinal studies are required to draw better conclusions on this issue. Secondly, we conducted a single center study with a small sample size, which does not allow for the findings to be generalized for all patients with CD. Thirdly, the selection of patients with functional dyspepsia for the control group could have impacted some points of the analysis since they are not a completely healthy population. 


\section{CONCLUSION}

Patients with moderate-severe $\mathrm{CD}$ on infliximab-induced clinical remission have the same level of physical activity in daily life, and exercise capacity compared to controls subjects, although they spend more time resting. QoL was impaired in domains of pain, vitality, social aspects and mental health in the control patients with functional dyspepsia, probably due to the visceral hypersensitivity of these subjects. However, because asymptomatic patients with quiescent $\mathrm{CD}$ have a similar low level of physical activity and more time lying down, it is important for strategies that promote physical activity be a component of regular care for the patients with $\mathrm{CD}$, so that patients may obtain optimal health benefits from exercise. Nonetheless, the real long-term effect of infliximab on physical activity in daily life is not known and further longitudinal studies are needed.

\section{Authors' contribution}

Cabalzar AL: acquisition of data, analysis and interpretation of data, drafting the manuscript, final approval before submission.
Azevedo FM: acquisition of data, drafting the manuscript, final approval before submission. Lucca FA: acquisition of data, revising the manuscript for critically important intellectual content, final approval before submission. Reboredo MM: conception and design of the study, analysis and interpretation of data, drafting the manuscript, final approval before submission. Malaguti C: conception and design of the study, analysis and interpretation of data, drafting the manuscript, final approval before submission. Chebli JMF: conception and design of the study, analysis and interpretation of data, drafting the manuscript, final approval before submission.

\section{Orcid}

Andrea Lemos Cabalzar: Orcid: 0000.0002.5963.1945.

Felipe Meirelles de Azevedo: Orcid: 0000. 0002.9520.4510.

Fernando de Azevedo Lucca: Orcid: 0000.0003.3401.9597.

Maycon de Moura Reboredo: Orcid: 0000.0001.8155-7414.

Carla Malaguti: Orcid: 0000.0002.6619.136X.

Júlio Maria Fonseca Chebli: Orcid: 0000.0003.1527.0663.

Cabalzar AL, Azevedo FM, Lucca FA, Reboredo MM, Malaguti C, Chebli JMF. Atividade física de vida diária, capacidade de exercício e qualidade de vida de pacientes com doença de Crohn em remissão induzida por infliximabe: um estudo preliminar. Arq Gastroenterol. 2019;56(4):351-6.

RESUMO - Contexto - A atividade física na vida diária e a capacidade de exercício não tem sido avaliada em pacientes com doença de Crohn. Objetivo Avaliar a atividade física na vida diária, capacidade de exercício, qualidade de vida e distúrbios de humor em pacientes com doença de Crohn moderada-grave em remissão induzida pelo infliximabe, e as possíveis associações entre essas variáveis. Métodos - Este foi um estudo preliminar transversal, envolvendo 26 pacientes com doença de Crohn e 20 controles. Os participantes realizaram as seguintes avaliações: atividade física na vida diária por meio de um acelerômetro triaxial, capacidade de exercício (teste de Shuttle), força de preensão palmar, qualidade de vida e distúrbios do humor. Resultados - O número de passos registrados ( $7446 \pm 3081$ vs $7898 \pm 2487)$, o tempo ativo $(80,6 \pm 42,0$ vs $89,7 \pm 24,3$ min), a distância caminhada no teste de Shuttle 665 (405) vs 710 (409) m, e a força de preensão manual 31(15) vs 29 (20) kgf não mostraram diferenças entre os pacientes com doença de Crohn e os controles, respectivamente. O tempo gasto na posição deitada 95.8 (68.8) vs 60.9 (74.7) min, e alguns domínios da qualidade de vida foram maiores nos pacientes com doença de Crohn. Nenhuma correlação foi observada entre a atividade física na vida diária e a qualidade de vida ou distúrbios do humor nos pacientes com doença de Crohn. Conclusão - Pacientes com doença de Crohn em remissão induzida por infliximabe, apesar de passarem mais tempo deitados, apresentam mesmo nível de atividade física e capacidade de exercício quando comparados aos controles.

DESCRITORES - Doença de Crohn. Tolerância ao exercício. Exercício.

\section{REFERENCES}

1. Ricci JER Júnior, Chebli LA, Ribeiro TCDR, Castro ACS, Gaburri PD, Pace FHDL, et al. Small-Intestinal Bacterial Overgrowth is Associated With Concurrent Intestinal Inflammation But Not With Systemic Inflammation in Crohn's Disease Patients. J Clin Gastroenterol. 2018;52:530-6.

2. Cosnes J, Gower-Rousseau C, Seksik P, Cortot A. Epidemiology and natural history of inflammatory bowel diseases. Gastroenterology. 2011;140:1785-94.

3. Cosnes J. Smoking, physical activity, nutrition and lifestyle: Environmental factors and their impact on IBD. Dig Dis. 2010;28:411-7.

4. Hold GL, Smith M, Grange C, Watt ER, El-Omar EM, Mukhopadhya I. Role of the gut microbiota in inflammatory bowel disease pathogenesis: What have we learnt in the past 10 years? World J Gastroenterol. 2014;20:1192-210.

5. Ng V, Millard W, Lebrun C, Howard J. Exercise and Crohn's disease: Speculations on potential benefits. Can J Gastroenterol. 2006;20:657-60.

6. Jones PD, Kappelman MD, Martin CF, Chen W, Sandler RS, Long MD. Exercise decreases risk of future active disease in inflammatory bowel disease patients in remission. Inflamm Bowel Dis. 2015;21:1063-71.

7. Klare P, Nigg J, Nold J, Haller B, Krug AB, Mair S, et al. The impact of a tenweek physical exercise program on health-related quality of life in patients with inflammatory bowel disease: A prospective randomized controlled trial. Digestion. 2015;91:239-47.
8. Abraham C, Cho JH. Inflammatory Bowel Disease. New Engl J Med. 2009;361:2066-78.

9. Levine JS, Burakoff R. Extraintestinal Manifestations of Inflammatory Bowel Disease. Gastroenterol Hepatol. 2011;7:255-63.

10. Lee N, Radford-smith G, Taaffe DR. Bone Loss in Crohn's Disease : Exercise as a Potential Countermeasure. Inflamm Bowel Dis. 2005;11:1108-18.

11. Abitbol V, Roux C, Chaussade S, Guillemant S, Kolta S, Dougados M, et al. Metabolic bone assessment in patients with inflammatory bowel disease. Gastroenterology. 1995; 108:417-22.

12. Subramaniam K, Fallon K, Ruut T, Mckay R, Shadbolt B, et al. Infliximab reverses inflammatory muscle wasting (sarcopenia) in Crohn's disease. Aliment Pharmacol Ther. 2015;41:419-28.

13. Maaser C, Sturm A, Vavricka SR, Kucharzik T, Fiorino G, Annese V, et al. ECCO-ESGAR Guideline for Diagnostic Assessment in IBD Part 1: Initial diagnosis, monitoring of known IBD, detection of complications.J Crohns Colitis. 2019;144-64

14. Elliott PR, Lennard-Jones JE, Hathway N. Simple Index of Crohn's Disease Activity. Lancet. 1980;315:876.

15. Stanghellini V, Chan FK, Hasler WL, Malagelada JR, Suzuki H, Tack J, et al. Gastroduodenal disorders. Gastroenterology. 2016;150:1380-92. 
16. Silverberg MS, Satsangi J, Ahmad T, Arnott ID, Bernstein CN, Brant SR, et al Toward an integrated clinical, molecular andserological classification of inflammatory bowel disease: Report of a Working Party of the 2005 Montreal World Congress of Gastroenterology. Can J Gastroenterol. 2005;19:5-36.

17. Welk GJ, McClain J, Ainsworth BE. Protocols for evaluating equivalency of accelerometer-based activity monitors. Med Sci Sport Exerc. 2012;44:39-49.

18. Florindo AA, Latorre MRDO. Validação e reprodutibilidade do questionário de Baecke de avaliação da atividade física habitual em homens adultos. Rev Bras Med do Esporte. 2003;9:129-35.

19. Singh SJ, Morgan MDL, Scott S, Walters D, Hardman AE. Development of a shuttle walking test of disability in patients with chronic airways obstruction. Thorax. 1992; 47:1019-24.

20. Borg GAV. Psychophysical bases of perceived exertion. Med Sci Sports Exerc. $1982 ; 14: 377-81$

21. Fess EE. Grip strength. In: Casanova JS, editor. Clinical Assessment Recommendations. $2^{\text {nd }}$ ed. Chicago: American Society of Hand Therapists; 1992.

22. Angst F, Drerup S, Werle S, Herren DB, Simmen BR, Goldhahn J. Prediction of grip and key pinch strength in 978 healthy subjects. BMC Musculoskelet Disord. 2010;11:94.

23. Ciconelli RM, Ferraz MB, Santos W, Meinão I, Quaresma MR. Tradução para a língua portuguesa e validação do questionário genérico de avaliação de qualidade de vida SF-36 (Brasil SF-36). Rev Bras Reumatol. 1999;39:143-50.

24. Pontes RMA, Miszputen SJ, Ferreira-Filho OF, Miranda C, Ferraz MB. Qualidade de vida em pacientes portadores de doença inflamatória intestinal: tradução para o português e validação do questionário Inflammatory Bowel Disease Questionnaire (IBDQ). Arq Gastroenterol. 2004;41:137-43.

25. Botega NJ, Bio MR, Zomignani MA, Júnior CG, Pereira WAB. Transtornos do humor em enfermaria de clínica médica e validação da escala de medida (HAD) de ansiedade e depressão.Rev Saúde Pública. 1995;29:355-63.

26. Lu ZL, Wang TR, Qiao YQ, Zheng Q, Sun Y, Lu JT, et al. Handgrip Strengh Index Predicts Nutritional Status as a Complement to Body Mass Index in Crohn's Disease. J Crohn's Colitis. 2016;10:1395-400.

27. Langenberg DR, Papandony MC, Gibson PR. Sleep and physical activity measured by accelerometry in Crohn's disease. Aliment Pharmacol Ther. 2015;41:991-1004.

28. Cabalzar AL, Oliveira DJF, Reboredo MM, Lucca FA, Chebli JMF, Malagut C. Muscle function and quality of life in the Crohn's disease. Fisioter Mov. 2017;30:337-45
29. Nakahigashi M, Yamamoto T. Increases in body mass index during infliximab therapy in patients with Crohn's disease: An open label prospective study. Cytokine. 2011;56:531-5.

30. Feagan BG, Yan S, Bala M, Bao W, Lichtenstein GR. The effects of infliximab maintenance therapy on health-related quality of life. Am J Gastroenterol 2003;98:2232-8.

31. Loftus EV, Feagan BG, Colombel JF, Rubin DT, Wu EQ, Yu AP, et al. Effects of adalimumab maintenance therapy on health-related quality of life of patients with Crohn's disease: Patient-reported outcomes of the CHARM trial. Am J Gastroenterol. 2008;103:3132-41.

32. Colombel JF, Sandborn WJ, Ghosh S, Wolf DC, Panaccione R, Feagan B, et al Four-year maintenance treatment with adalimumab in patients with moderately to severely active ulcerative colitis: Data from ULTRA 1, 2, and 3. Am J Gastroenterol. 2014;109:1771-80.

33. Leblanc K, Moli MH, Parker CE, MacDonald JK. The impact of biological interventions for ulcerative colitis on health-related quality of life. Cochrane Database Syst Rev. 2015. DOI:10.1002/14651858.CD008655.pub3.

34. Holdam ASK, Bager P, Dahlerup JF. Biological therapy increases the health-related quality of life in patients with inflammatory bowel disease in a clinical setting. Scand J Gastroenterol. 2016;51:706-11.

35. Shephard RJ. The Case for Increased Physical Activity in Chronic Inflammatory Bowel Disease: A Brief Review. Int J Sports Med. 2016;37:505-15.

36. Khalili H, Ananthakrishnan AN, Konijeti GG, Liao X, Higuchi LM, Fuchs CS, et al. Physical activity and risk of inflammatory bowel disease: prospective study from the Nurses' Health Study cohorts. BMJ 2013. DOI:10.1136/bmj.f6633.

37. Sonnenberg A, Walker JT. Occupational mortality associated with inflammatory bowel disease in the United States 1984-1998. Inflamm Bowel Dis. 2012;18: 1249-53.

38. Persson PG, Leijonmarck CE, Bernell O, Hellers G, Ahlbom A. Risk Indicators for Inflammatory Bowel-Disease. Int J Epidemiol. 1993;22:268-72.

39. Reif S, Klein I, Lubin F, Farbstein M, Hallak A, Gilat T. Pre-illness dietary factors in inflammatory bowel disease. Gut. 1997;40:754-60.

40. Cucino C, Sonnenberg A. Occupational mortality from inflammatory bowe disease in the United States 1991-1996. Am J Gastroenterol. 2001;96:1101-5.

41. Melinder C, Hiyoshi A, Hussein O, Halfvarson J, Ekbom A, Montgomery S Physical Fitness in Adolescence and Subsequent Inflammatory Bowel Disease Risk. Clin Transl Gastroenterol. 2015;6:e121. 